Erratum

Pneumologe $2019 \cdot 16: 211$

https://doi.org/10.1007/s10405-019-0249-3

Online publiziert: 16. April 2019

(c) Springer Medizin Verlag GmbH, ein Teil von Springer Nature 2019
C. Zwafink · J. Benedikter · A. Nerlich · H. Popper · M. Weinmüller · F. J. Meyer

Lungenzentrum München, Klinik für Pneumologie und Pneumologische Onkologie, Klinikum

Bogenhausen, Städtisches Klinikum München GmbH, München, Deutschland

\section{Erratum zu: Protrahierter Husten nach harmlosem Atemwegsinfekt?}

\section{Erratum zu:}

Pneumologe 2019

https://doi.org/10.1007/s10405-019-

0239-5

Die Abb. 4 des Beitrags wurde freundlicherweise von Herrn Professor H. Popper, Graz, zur Verfügung gestellt. Wir bitten Sie, die fehlende Copyrightangabe in der Legende $\mathrm{zu}$ entschuldigen und $\mathrm{zu}$ beachten, dass das Copyright für diese Abbildung bei Herrn Prof. Popper verbleibt.

\section{Korrespondenzadresse}

\section{Zwafink}

Lungenzentrum München, Klinik für Pneumologie und Pneumologische Onkologie, Klinikum Bogenhausen, Städtisches Klinikum München $\mathrm{GmbH}$

Englschalkingerstr. 77, 81925 München, Deutschland

carina.zwafink@klinikum-muenchen.de 